\title{
ENSINO DE CIÊNCIAS FREIRIANO: uma análise do livro Minha dança tem história, de bell hooks
}

\author{
Eloize Braga Quintanilha \\ Fernanda Antunes Gomes da Costa
}

\section{Resumo}

Este artigo, de base teórica, tem por objetivo promover aproximações entre o Ensino de Ciências e o legado freiriano a partir de narrativas femininas negras para infância. Acreditamos ser fundamental pensarmos um mundo outro, tendo a escola como local de transformação e de engajamento na luta por uma sociedade menos injusta. Para tal, teceremos aproximações entre Paulo Freire e bell hooks ${ }^{1}$, buscando mostrar ser possível epistemologias comprometidas com uma verdadeira mudança social, tão necessária diante dos desafios impostos pela conjuntura atual. Sendo este ano de 2021 o ao do centenário de Paulo Freire, se faz urgente o retorno ao seu pensamento e prática libertadora, assim como reavivar experiências, reencantar o futuro. Portanto, buscaremos pensar de que forma a literatura pode ser uma narrativa potente na busca por fazer emergir vozes silenciadas, assim como o ensino de ciências pode se mostrar também parte fundamental para uma formação humana capaz de produzir conhecimento em prol da justiça social. Para isto, vamos revistar e ressignificar a palavra freiriana e, também, a literatura infantil de bell hooks, duas vozes que denunciam as desigualdades, assim como anunciam possibilidades de ser e estar em um mundo verdadeiramente igualitário. Acreditamos assim, celebrar Paulo Freire e pensar um mundo outro possível.

Palavras-chave: literatura infantil; ensino de ciências; relações étnico-raciais.

FREIREAN SCIENCE EDUCATION: an analysis of the book $M y$ dance bas history, a bell hooks

\begin{abstract}
This article, with a theoretical basis, aims to promote approximations between Science Education and the Freirian legacy based on black female narratives for childhood. We believe it is essential to think of a different world, with the school as a place of transformation and engagement in the struggle for a less unfair society. To this end, we will weave rapprochements between Paulo Freire and bell hooks, seeking to show that it is possible to have epistemologies committed to a true social change, so necessary in the face of the challenges imposed by the current conjuncture. This year 2021 being the year of Paulo Freire's centenary, there is an urgent need to return to his liberating thought and practice, as well as to revive experiences, reenchant the future. Therefore, we will try to think about how literature can be a powerful narrative in the search for the emergence of silenced voices, just as science teaching can also prove to be a fundamental part for a human formation capable of producing knowledge in favor of social justice. For this, we will search and reframe the Freirian word and also the children's literature of bell hooks, two voices that denounce inequalities, as well as announce possibilities of being and being in a truly egalitarian world. We believe, therefore, to celebrate Paulo Freire and think of a possible other world.
\end{abstract}

Keywords: children's literature; science teaching; ethnic-racial relations. ${ }^{1}$ A autora utiliza o próprio nome escrito todo em letras minúsculas, justificando que a ênfase de seu trabalho deve ser
dada ao conteúdo de sua escrita e não à sua pessoa. 
DOI: $10.12957 /$ teias.2021.60162

\section{FREIRIANO ENSEÑANZA DE LAS CIENCIAS: un análisis del libro Mi danza tiene historia, de bell hooks}

\section{Resumen}

Este artículo, con una base teórica, tiene como objetivo promover aproximaciones entre la Educación Científica y el legado freiriano a partir de narrativas femeninas negras para la infancia. Creemos que es fundamental pensar en un mundo diferente, con la escuela como un lugar de transformación y compromiso en la lucha por una sociedad menos injusta. Para ello, tejeremos acercamientos entre Paulo Freire y bell hooks, buscando mostrar que es posible tener epistemologías comprometidas con un verdadero cambio social, tan necesario ante los desafíos que impone la situación actual. Siendo este año 2021 el año del centenario de Paulo Freire, hay una necesidad urgente de volver a su pensamiento y práctica liberadora, así como de revivir experiencias, reencantar el futuro. Por lo tanto, intentaremos pensar en cómo la literatura puede ser una narrativa poderosa en la búsqueda de hacer emerger voces silenciadas, así como la enseñanza de las ciencias también puede resultar parte fundamental para una formación humana capaz de producir conocimientos a favor de la justicia social. Para ello, buscaremos y replantearemos la palabra freiriana y también la literatura infantil de bell hooks, dos voces que denuncian las desigualdades, además de anunciar posibilidades de ser y estar en un mundo verdaderamente igualitario. Creemos, por tanto, celebrar a Paulo Freire y pensar en un otro mundo posible.

Palabras clave: literatura infantil; enseñanza de las ciencias; relaciones étnico-raciales.

\section{É PRECISO ESPERANÇAR UM MUNDO OUT'RO: INTRODUÇÃO}

Com a chegada da Covid-19, enfrentamos em nosso país muitos desafios. Além das sequelas de uma doença ainda não controlada, presenciamos as consequências sociais em um Brasil marcado por uma severa desigualdade histórica. Notícias apontam que a população negra e pobre é a mais afetada pela pandemia (Portal G1, 2020), pois compõe a linha de frente de trabalhadores de serviços essenciais e informais, que estão mais expostos ao vírus, além de muitas vezes, residir em locais com saneamento básico precário. Assim, pensar um mundo outro possível é buscar propostas de enfrentamento a esta realidade, sendo a educação espaço capaz de tecer críticas e de potencializar caminhos para novas utopias a uma sociedade brasileira que necessita desejar um futuro pós-pandêmico menos injusto.

Para que a escola possa contribuir na luta por igualdade e justiça, ela precisa ser capaz de se mostrar engajada, lugar de resistências e de verdadeiras práticas para liberdade, como o acolhimento a vozes silenciadas historicamente e que estão a ser afetadas de forma severa na atual conjuntura. Precisamos, como nunca, de uma verdadeira escola que seja lugar-potencial de sonhos e de utopias. Paulo Freire, cujo centenário é comemorado neste ano de 2021, nos deixou um legado pedagógico e epistemológico que nos provoca, ou melhor, nos convoca ao compromisso com uma formação humana capaz de transformar, de reencantar realidades, de narrar transformações verdadeiras. Para além, ele nos deixou um pensamento amoroso, em que nos mostra a importância de anunciarmos e, como educadores, proporcionarmos o anúncio da nossa palavra e da palavra de nossos educandos. Para o patrono da educação brasileira, a "[...] existência, porque humana, não pode ser muda, silenciosa, nem tampouco pode nutrir-se de falsas palavras, mas de palavras verdadeiras, com que os homens transformam o mundo" (FREIRE, 2019, p. 108).

Considerando a dimensão social, cultural e política da educação, pensamos ser urgente fazer emergir palavras que sejam capazes de romper com o silencio, ressignificando a dimensão transformadora do conhecimento em nossas salas de aula frente aos obstáculos impostos ao presente, principalmente aos mais vulneráveis socialmente. Para isso, a história dos oprimidos, ainda velada, precisa vir à tona, mostrando ser a palavra, que é práxis, não um “[...] privilégio de 
alguns homens, mas direito de todos os homens" (FREIRE, 2019, p. 109). O diálogo e a compreensão da necessidade da luta por igualdade podem potencializar as narrativas que atravessam a nossa prática docente.

Dessa forma, nossa proposta de reflexão teórica aposta nas narrativas que emergem da literatura para a infância, produzida por vozes-mulheres negras (EVARISTO, 2017), anunciando a importância da representatividade como fundamental a um mundo plenamente igualitário. Nossa voz escolhida é a da professora e intelectual negra bell hooks cuja obra é declaradamente inspirada na filosofia e prática freirianas. bell hooks é autora de obras infantis e traz o seguinte relato sobre sua produção escrita para crianças:

Obviamente, ao tentar escrever livros para libertar crianças, encarai a realidade de que várias pessoas estão mais confortáveis com as formas habituais de enxergar e pensar nosso corpo, nossa personalidade, mesmo que essas formas habituais estejam enraizadas em estereótipos racistas e machistas (HOOKS, 2020, p. 2018)

Em sua reflexão, a autora mostra a necessidade de uma nova forma de pensar e de enxergar a fim de promover a mudança de mentes, promovendo, assim a liberdade como uma prática permanente: “[...] manter a mente aberta é uma exigência essencial do pensamento crítico (HOOKS, 2020, p. 35). Paulo Freire, por sua vez, também nos mostrou ser fundamental pesarmos caminhos para uma "[...] pedagogia para homens livres" (FREIRE, 2007, p. 14). O encontro dialógico entre esses dois professores e teóricos nos conduz a uma leitura crítica e engajada do mundo.

Acreditamos ser na infância e para todas e todos, o benefício do contato com narrativas plurais. Narrativas essas que devem atravessar todo o currículo escolar, incluindo o Ensino de Ciências, principalmente em tempos em que a verdade científica vem sendo questionada. Diante de tamanho desafio, nosso artigo vem problematizar reflexões para a seguinte questão: A literatura infantil feminina e negra pode potencializar a discussão sobre as desigualdades também no Ensino de Ciências a fim de colaborar para uma formação científica comprometida com a prática para liberdade, com um mundo mais justo e igualitário?

Para isso, teremos Paulo Freire e bell hooks a nos orientar pelos percursos teóricos deste texto, assim como autoras do ensino de ciências e da educação alinhadas aos objetivos de uma práxis emancipadora e contra-hegemônica. Teceremos uma análise da obra Minha dança tem história (HOOKS, 2019), pensando caminhos possíveis à interface literatura e ciências na tentativa de colaborar com propostas para sala de aula que tenham como foco a formação humana, a valorização das diferentes formas de pensar e a sensibilidade. Acreditamos, assim, celebrar, neste artigo, Paulo Freire de forma atual e de maneira a buscar novos olhares capazes de reencantar o mundo pela educação.

\section{PAULO FREIRE E BELL HOOKS: SABEDORIAS E PRÁTICAS PARA PERCURSOS TEÓRICOS}

Toda prática educativa que se fundamente numa perspectiva de matriz freiriana deve partir do conhecimento trazido pelo aluno. Independentemente da idade ou nível educacional do sujeito, é preciso que a sua história seja considerada e o seu conhecimento valorizado para que a ação educativa seja significativa. Nosso texto buscou caminhar ao encontro dos princípios freirianos em defesa de um ensino de ciências que propicie ao estudante uma visão crítica da realidade. Nesse contexto, o trabalho educativo em sala de aula pode ser compreendido na perspectiva de construir 
condições para a problematização da realidade com vista a transformação da sociedade. Formar o aluno para a vida vai além de um ensino tradicional, em que o professor ensina e o aluno aprende. Formar o aluno para a vida trata-se de um processo de emancipação, em que o professor é o mediador da aprendizagem e o estudante aprende através da discussão de problemas sociais que levam a um pensar sobre o mundo e a um agir capaz de modificar a sua história de vida por meio da ação coletiva. No entanto, compreendemos que o ensino de ciências é visto, por muitos, como um saber desvinculado da vida real. Por isso, propomos a literatura como um caminho para novas possibilidades de ensino e de aprendizagem.

A ciência é um conhecimento tão básico para a formação cidadã, quanto as habilidades de leitura e escrita. Viver exige mais do que o conhecimento comum e cotidiano. Atos simples como trocar uma lâmpada, comprar um produto alimentício e utilizar um eletrodoméstico demandam um repertório de saberes que está além do saber intuitivo. Um dos equívocos das práticas pedagógicas para o ensino de ciências em sala de aula é a fragmentação do conteúdo como se os fenômenos naturais e sociais não tivessem relação entre si, o que é um obstáculo para uma formação crítica, já que impedem uma ação contextualizada por parte dos estudantes e os impedem de serem sujeitos ativos na transformação da realidade na qual estão inseridos. As ciências naturais não estão isoladas das outras disciplinas escolares, nem dos pressupostos tecnológicos e econômicos que permeiam a construção das sociedades em um dado espaço de tempo. A abordagem entre a ciência e as outras áreas de ensino possibilita aos alunos a compreensão dos avanços científicos presentes em seu cotidiano. O ensino de ciências é inseparável dos processos políticos e sociais de uma sociedade e não deve ser visto como um saber acumulado ou meramente pedagógico, mas sim como um enfrentamento entre os processos internos do ensino e sua relação com a exterioridade (ARROYO, 1988).

Surge, então, a necessidade de se pensar a alfabetização científica desde a infância, ou seja, trabalhar o domínio dos conhecimentos científicos e tecnológicos necessários para o desenvolvimento da vida diária desde os anos iniciais de escolarização. O ensino de ciências naturais tem buscado romper com o ensino fragmentado e desconectado do cotidiano dos estudantes. Com o avanço da tecnologia, surge a necessidade de um ensino que promova a valorização dos conhecimentos que os alunos constroem através da interação com o outro por meio da linguagem. Essas experiências devem ser ampliadas em sala de aula, em que o saber científico deverá dialogar com as competências dos alunos, promovendo assim, a produção de novos saberes (CHASSOT, 2003).

Para Paulo Freire (1996), a educação deve servir para promoção da humanização e não para domesticação e coisificação dos sujeitos. Deve servir para a solidariedade e não para a competição. Deve promover a vida em sociedade e não o individualismo. A autonomia ao invés da alienação. A reflexão crítica no lugar do simplismo. Para isso, a ação educadora deve ser pautada em ética para a vida humana, contribuindo para do desenvolvimento das potencialidades, promovendo a dignidade e fomentando a autonomia responsável dos sujeitos. O professor como promotor da liberdade. A educação como forma de libertação. A educação que liberta, que não oprime, que não discrimina, mas que prepara para a luta contra qualquer tipo de dominação ou autoritarismo.

Ou seja, o sujeito atua ativamente na aquisição e produção do seu próprio conhecimento. Quando o processo educativo não observa essa premissa, a aprendizagem crítica dos educandos fica prejudicada, "Quanto mais é simples e dócil o receptor dos conteúdos com os quais, em nome do saber, é 'enchido' por seus professores, tanto menos pode pensar e apenas repete". (FREIRE, 2011, p. 68). O estudante precisa ser desafiado. O conhecimento científico deve partir da problematização em torno do próprio saber que o educando deve incorporar. $\mathrm{Na}$ pedagogia tradicional, os saberes prévios dos alunos não são considerados. Como resultado, o conhecimento 
perde o sentido devido à ausência de vínculo com a realidade do aluno. Em contrapartida, Freire (2011) afirma que essa sabedoria precisa ser valorizada e trazida para o contexto da sala de aula como ponto inicial para o diálogo entre educandos e educadores, proporcionando aos educandos, uma maior compreensão e até mesmo a superação de suas situações limites. "Os saberes prévios dos estudantes devem ser levados em consideração como ponto de partida no processo de mediação didática, entretanto eles são uma via para o estudo dos conhecimentos científicos" (PINHEIRO, 2016, p. 22). A ideia não é substituir um saber pelo outro, mas iniciar uma mudança de visão de mundo a partir dos saberes dos próprios educandos.

Partimos da ideia de que a leitura é um dos momentos mais prazerosos para as crianças na escola. A leitura proporciona o acesso à cultura e deve ser estimulada desde os primeiros anos de escolarização. O uso da literatura infantil em sala de aula pode representar uma possibilidade real de rompimento com o ensino tradicional e desconectado da vida do estudante. $O$ fato desse tipo de leitura fornecer acesso à realidade a partir de uma fantasia escrita dá à literatura infantil uma função formadora que aproxima a criança do conhecimento de mundo. Para Regina Zilberman (2003), a literatura infantil atua como agente do conhecimento, proporcionando o questionamento dos valores sociais, propiciando elementos para a emancipação social, despertando a curiosidade e desenvolvendo o espírito crítico. A história de ficção infantil apresenta relações existentes no mundo real que a criança não consegue perceber por conta própria. Outro importante elemento da literatura infantil é a linguagem, mediadora entre a criança e o mundo. A literatura é uma linguagem que favorece a compreensão dos saberes no ensino que, de acordo com Paulo Freire (1987), deve ser dialógico e emancipador.

O uso de obras literárias no ensino de ciências pode estimular a participação dos estudantes na sala de aula, incentivando o interesse pela ciência e favorecendo o aprendizado. A literatura ainda facilita a contextualização da realidade com a vida cotidiana, ampliando a prática da leitura e da escrita e facilitando a abordagem de temas culturais, sociais e políticos, em conexão com as ciências. O professor precisa utilizar esse recurso de forma dinâmica, articulando os livros infantis com o ensino de ciências em sala de aula, abordando temas do cotidiano do aluno e relacionando o imaginário infantil com conhecimentos do mundo real (PIASSI, ARAÚJO, 2012).

$\mathrm{Na}$ área de ciências, a literatura infantil pode ser utilizada com o objetivo de despertar a curiosidade das crianças, incentivando e levantando hipóteses na construção do conhecimento científico. O livro literário não precisa estar focado na instrução ou ter como finalidades a transmissão de um conteúdo. Ao assumir um papel educacional, a literatura garante a importância da formação da criança e serve como agente de transformação, levando a escola a romper com o ensino tradicional. Propor a literatura como forma de ensino para os diferentes componentes didáticos, não significa restringi-la a uma mera estratégia temática, mas sim aproveitar a riqueza do acervo literário para agregar novos conhecimentos e diferentes olhares ao que está sendo estudado. Através da literatura infantil, o ensino de ciências pode se transformar em um ensino contextualizado e prazeroso, apontando para um conhecimento de mundo que permita uma visão ética dos direitos e deveres perante toda a sociedade.

Paulo Freire defende que a educação é uma forma de intervenção na vida coletiva através da manutenção da realidade ou de sua superação. A educação deve servir para tornar a sociedade mais livre, humana, justa e democrática, contribuindo com os processos de luta política contra a exploração e dominação, mas a favor da transformação da sociedade em que vivemos. A neutralidade é uma forma covarde de se abster, pois ela reforça a opressão e fortalece o opressor. A qualidade política da educação possui a capacidade de superação dessa neutralidade, promovendo a luta contra a dominação do oprimido e contribuindo para a transformação da sociedade (FEIRE, 1996) 
Em diálogo com Paulo Freire, bell hooks (2013) afirma que as questões raciais e de classe ainda permanecem abafadas em sala de aula. As discussões sobre o quanto o ambiente de sala de aula pode ser transformado em um local de inclusão ainda são insuficientes. É preciso reconhecer que o estilo de ensino tem que mudar. Nesse sentido, Paulo Freire alerta: "Não é no silêncio que os homens se fazem, mas na palavra, no trabalho, na ação-reflexão" (FREIRE, 1987, p. 90). Para a autora, a escola deve ser um local fundamentalmente político e de resistência na luta contra o racismo: "[...] o corpo docente precisava desaprender o racismo para aprender sobre a colonização e a descolonização e compreender plenamente a necessidade de criar uma experiência democrática de aprendizado das artes liberais" (HOOKS, 2013, p. 55). A autora compreende a prática educacional como um lugar político e de resistência nas lutas antirracistas e nas lutas feministas.

Nesse sentido, estudantes e docentes devem ser vistos em sua integridade e todos os tipos de conhecimento precisam ser valorizados, incluindo aqueles que partem das práticas cotidianas. O papel desempenhado pela educação escolar no desenvolvimento infantil, muito se aproxima do que Nilma Lino Gomes (2017) aborda como a concepção de educação humanizadora de Paulo Freire. Segundo a autora, Paulo Freire entendia a educação não apenas como um problema pedagógico, mas também como um problema social. O papel da escola é contribuir com a humanização, o que implica em reconhecer a desumanização como uma realidade histórica. Para a autora, a obra do educador busca algo realizável, busca por uma educação como projeto emancipatório possível (GOMES, 2017).

O racismo constitui-se em um sistema de opressão e dominação que hierarquiza grupos e povos, pautado na ideia de superioridade ou inferioridade racial. "No Brasil, ele opera com a ideologia de raça biológica, travestida no mito da democracia racial (harmonia racial) que se nutre, entre outras coisas, do potencial da miscigenação brasileira" (GOMES, 2017, p. 98). Os fatores físicos, como cor da pele, cabelos, formato do nariz ou do corpo são utilizados pela ideologia de "raça biológica" como argumentos de inferiorização e classificação entre negros e brancos no Brasil (GOMES, 2017).

Quando enfrentado na infância, o racismo pode acarretar estressores agudos, compreendidos como fator explicativo para as dificuldades encontradas pelos alunos negros no ambiente educacional. A vulnerabilidade social dessas crianças se perpetua através da falsa democracia racial, quando se considera a inexistência de práticas racistas no meio escolar. Tais problemas podem interferir negativamente na trajetória escolar, sendo revelados através de dificuldades de aprendizagem, gerando sérias consequências para a construção da identidade, levando o estudante a evasão escolar e consequentemente à exclusão social. A educação escolar desempenha um importante papel no desenvolvimento físico, emocional e social das crianças, especialmente daquelas que vivem expostas a fatores de vulnerabilidade social (CAVALLEIRO, 2000).

Para bell hooks (2013), o estudo é um ato de resistência às estratégias coloniais. Daí a importância de se ter um compromisso com uma pedagogia engajada como expressão de ativismo político, na qual a presença de cada aluno seja valorizada e todos possam contribuir com a dinâmica da sala de aula. Faz-se necessário a reflexão permanente sobre o racismo na escola e na sociedade. O reconhecimento e a valorização da diversidade cultural e étnico-racial brasileira deve considerar a diversidade presente no ambiente escolar e utilizá-la de forma integradora através de ações que fortaleçam a identidade e autoestima dos educandos.

Diante dessa afirmação, propomos um ensino de ciências que se aproxime da realidade do estudante, rompa com o mito da democracia racial no Brasil e promova o protagonismo da cultura negra e africana em sala de aula. Para tanto, a Lei n. 10.639/03, que altera a Lei n. 9394/96 (Lei de Diretrizes e Bases da Educação Nacional, LDBEN), inclui a obrigatoriedade do ensino da História 
e Cultura Afro-Brasileira no currículo oficial da rede de ensino nacional. Romper com o mito da democracia racial a partir do ensino escolar, significa problematizar de que forma os conteúdos escolares influenciam as relações étnico-raciais nas escolas. Entende-se como educação das relações étnico-raciais o processo de reconstrução dessas relações que promovem a existência de uma hierarquia racial e que contribuem para reforçar as desigualdades em todos os setores da sociedade. Inserir a temática étnico-racial nas aulas de ciências trata-se de assumir uma postura de resistência diante de um currículo que pouco tem contribuído para problematização das relações étnico-raciais e para a superação do mito da democratização racial (PINHEIRO, ROSA, 2018).

Como recurso metodológico, propomos a análise de um livro infantil de autoria feminina e negra, proporcionando uma reflexão sobre a prática escolar e metodologias outras possíveis para o ensino de ciências. A escolha por trabalhar com narrativas femininas e negras se deu por constituírem produções que denunciam o silenciamento político e cultural sofrido pelos grupos desviantes, como as mulheres e a população negra. As representações femininas na literatura infantil podem contribuir para a construção de modelos comportamentais que representam inconformismos ou resistências, construindo um imaginário capaz de transformar as estruturas do leitor e levando-o a uma ação comunicativa. Trazer leituras de autoria feminina e negra para a sala de aula derruba estereótipos que ainda precisam ser trabalhados a partir do reconhecimento das dinâmicas de raça, gênero e classe social. Glória Pondé (2018) afirma que a percepção feminina se identifica com o posicionamento de grupos sociais dominados, como as crianças, os negros, os idosos e os pobres. Ela ainda reforça que a discriminação desses grupos é percebida pelo isolamento cotidiano que causa solidão, insatisfação, repressão e culpa.

Como caminho para a análise, propomos uma abordagem que evidencie aspectos diretamente relacionados ao estudo das relações étnico-raciais e do ensino de ciências, mesmo que estejam implícitos nas histórias analisadas. Buscamos identificar possíveis tópicos de abordagem nas aulas de ciências para o primeiro segmento do ensino fundamental a partir de obras literárias negras que não foram produzidas com o objetivo de um trabalho didático de temas científicos e apresentar possibilidades de atividades relacionadas a aprendizagem de conteúdos científicos no livro analisado. Os critérios propostos para a análise do livro foram:

a) $\mathrm{O}$ texto - A escolha por um texto deve considerar a idade e a série na qual a atividade será trabalhada. É importante que sejam observados os tipos de letra, a quantidade de escrita no texto e a capacidade de leitura dos alunos que participarão das atividades.

b) As imagens - As ilustrações devem ser observadas como um dos principais critérios de escolha, pois a imagem acessa e estimula o imaginário da criança. Deve-se observar as cores, a sequência das imagens e a sua contribuição para a compreensão da narrativa.

c) O tema - considerando que o estudo das relações étnico-raciais é um direito garantido pela Lei n. 10.639/03, buscamos um ensino de ciências mais humanitário, significativo e ao mesmo tempo instigante para a faixa etária trabalhada. O tema racial e de gênero foi escolhido por apresentar uma temática necessária para a educação como direito humano e social.

d) A autoria - a autoria do livro também deve ser um critério de escolha da obra. Pelo trabalho ter uma temática racial e de gênero, optamos por trabalhar com um livro infantil da escritora e educadora bell hooks.

MINHA DANÇA TEM HISTÓRIA: TECENDO ANÁLISE E LEITURA PARA UMA CIÊNCIA OUTRA 
O livro Minha dança tem história (2019), escrito por bell hooks e ilustrado por Chris Raschka foi publicado no Brasil em 2019 pela Boitatá, selo infanto-juvenil da editora Boitempo. Traduzido por Nina Rizzi, o livro utiliza a cultura do hip-hop para falar sobre a busca da masculinidade nas vidas dos meninos a partir da dança dos B-Boys. Este livro foi selecionado por possuir uma abordagem que trabalha sentimentos e emoções a partir de uma narrativa infantil sobre uma cultura tradicionalmente negra: o hip-hop. As letras do livro são de imprensa e a narrativa é feita em primeira pessoa em formato de rimas que lembram a estrutura de uma letra de rap. Esse livro é ideal para ser trabalhado de forma lúdica com os alunos em fase de alfabetização. Apresenta textos curtos de forma rimada, explora bem as imagens e possui como tema principal, uma abordagem sobre a vida dos meninos e as contradições encontradas na busca pela masculinidade.

\section{Figura 1: Capa do livro Minha dança tem história.}

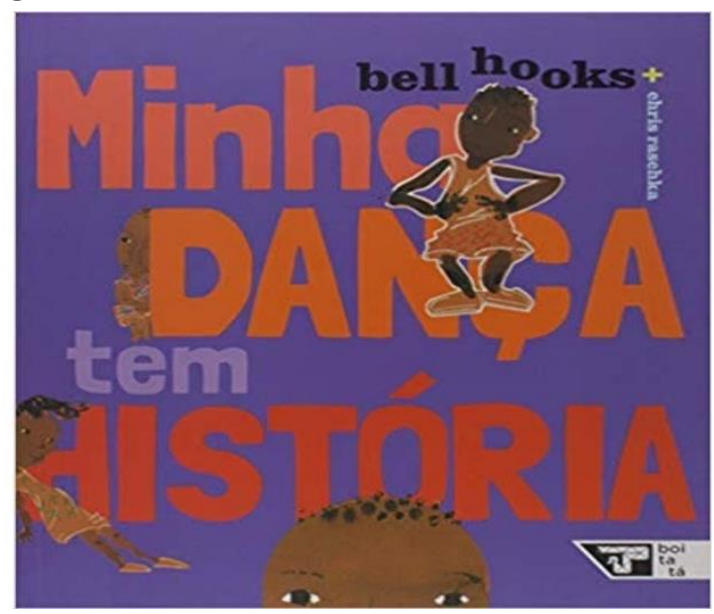

Fonte: bell hooks (2019).

O hip-hop é um gênero musical que surgiu nos Estados Unidos na década de 1970, principalmente nas comunidades afro e latino-americanas da cidade de Nova York. (LOURENÇO, 2020). Mais que um gênero musical, o hip-hop é um estilo de vida de povos que foram marginalizados e motivo de orgulho para seus praticantes. B-boy é um termo utilizado para designar o dançarino de breaking, os break-boys e as break-girls. Segundo Adelekun (2019), quando o breaking começou, ele não era somente uma dança. O breaking era um estilo de vida para as crianças da periferia:

Ser B-Boy ou B-Girl era, e ainda é, vestir-se de uma certa maneira, ouvir a música da cultura hip-hop, andar e conversar de uma certa maneira, e também praticar (ou pelo menos ter interesse) nos outros três elementos do bip-hop: grafite, MCing e DJing (ADELEKUN, 2019).

A intelectual bell hooks nos apresenta então, ao menino "Bibói. Bibói é um menino bonito, 'Bem bonito"' (HOOKS, 2019, p. 7). Ele dança, ele corre, ele pula. Ele é Bibói. Ele é Bibói sorrindo ou chorando, dançando ou quietinho. Ele gosta de carinho e possui um grande coração. É sonhador e possui momentos de introspecção. Está sempre pronto para “[...] quebrar, pra brilhar e brincar" (HOOKS, 2019, p. 27). Ele é apaixonado por ser que ele é. É importante, ao se trabalhar com a literatura infantil, que a abordagem de qualquer conteúdo inicie localizando a história no espaço e no tempo. Dessa forma, o professor de ciências das séries iniciais pode utilizar esse livro 
para abordar relações étnico-raciais a partir da cultura do hip-hop, sua história e sua origem. Em seguida, o estudo pode ser direcionado para o conteúdo de corpo humano, os cinco sentidos, movimentos, expressões e sentimentos.

A autora consegue captar a essência do que é ser um menino dentro da cultura do hiph-hop ao abordar a masculinidade do menino Bibói de uma forma sensível, mostrando que menino também chora, também dança, também é carinhoso. Através da sua dança, o personagem encontra novas formas de expressar suas emoções, sua sensibilidade e sua inclinação pela arte. O conteúdo de gênero e sexualidade também pode ser abordado a partir dessa história. Questões que podem ser levantadas pelo professor: Homem chora? Mulher chora? Por que homem não pode chorar e mulher pode? Quais são as diferenças físicas e emocionais que levaram a sociedade a acreditar que homem não pode chorar? A partir desses questionamentos, o professor pode abordar questões emocionais, culturais e físicas sobre o desenvolvimento corporal e sexual de meninos e meninas, a construção da identidade, o respeito a sexualidade e aos gêneros e até mesmo, conteúdos de higiene e saúde.

A ilustração do livro contribui com essa abordagem sensível da autora ao ocupar toda extensão das páginas. As imagens do menino Bibói estão em toda a parte, demonstrando que os movimentos de sua dança se misturam com a movimentação que ocorre em sua vida. $O$ fundo de todas as páginas é na cor marrom e nas imagens predominam os tons de marrom e preto, dando a impressão de que a história se passa em uma comunidade negra, o que nos remete aos guetos de hip-hop.

Figura 2: Bibói contando a sua história

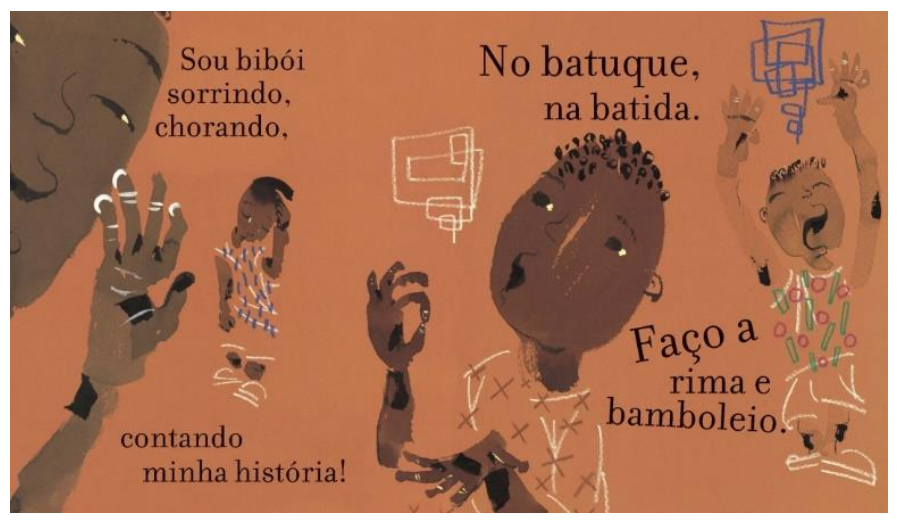

Fonte: bell hooks (2019).

A partir da história de Bibói, o professor pode abordar em sala de aula a cultura da população negra, seus costumes, origens e tradições. Para Freire (1987), a conscientização do oprimido sobre as suas próprias condições de vida é o que o leva a lutar contra a violência dos opressores. Essa forma de educação favorece ao estudante o reconhecimento de seu próprio lugar na sociedade onde vive. Conhecer a origem dos seus hábitos, de sua dança e de sua música, contribui para que a criança negra se orgulhe de suas raízes e valorize não somente a sua história, mas também a história da sociedade onde se encontra.

Nesta história, o corpo humano é mais uma vez o protagonista para a aplicação de conhecimentos científicos. O trabalho com a dança pode problematizar discussões sobre os movimentos corporais, o cuidado, a valorização e o respeito pelo próprio corpo e pelo corpo do 
outro. Sentimentos como alegria, tristeza, raiva e amor também podem ser abordados a partir da leitura do livro.

Sendo a música um tipo de transmissão oral, podemos considerar, também, que se a concepção africana de Hampâté Bâ fosse acatada pela ciência, todos entenderiam a natureza como parte de si e como algo vivo que interage conosco e com a nossa própria vida. Para o escritor, tudo é palavra, inclusive a natureza. "Ela é ao mesmo tempo religião, conhecimento, ciência natural, iniciação à arte, história, divertimento e recreação, [...]” (HAMPATÉ BÂ, 2010, p. 169).

Esse livro é importante por ser escrito por uma mulher negra que vê a educação como uma forma de promover a igualdade para todos. bell hooks (2020) acredita na literatura infantil como caminho, pois esse é seu segundo livro para crianças. Dessa forma, a autora nos mostra que a educação para as relações étnico-raciais precisa acontecer desde os primeiros anos tanto na escola, quanto em casa e que a literatura pode ser um caminho humanizador. Em seu livro Ensinando pensamento crítico, bell hooks relata o quanto é "[...] difícil escrever livros cujos personagens principais são homens antipatriarcais e não machistas." (HOOKS, 2020, p. 2018). Para a autora, a sociedade não é amável com as crianças, especialmente com os meninos. Utilizar uma narrativa feminina que expresse a visão masculina a partir de uma totalidade emocional e não patriarcal é reconhecer que o que é ser menino. E assim como Paulo Freire que defendia uma educação libertadora, bell hooks acredita que seus livros infantis a ajudam a "[...] libertar crianças." (HOOKS, 2020, p. 221). Acreditamos também que o diálogo entre Freire e hooks, entre literatura e ciência venha a ser uma possibilidade para uma a produção de uma ciência outra, ou seja, um fazer científico comprometido com a justiça social, com um mundo menos injusto para todas, todos.

\section{CONSIDERAÇÕES FINAIS}

Pautada na teoria de Paulo Freire e na educação transgressora de bell hooks, buscamos fazer emergir três vozes silenciadas no meio científico: a vOz da mulher, a vOz do negro e a vOz da criança. A análise do livro Minha dança tem história (2019) buscou identificar possíveis tópicos de abordagem nas aulas de ciências, a partir de uma literatura que aproxima a educação escolar do cotidiano do estudante. Ensinar ciências a partir de obras literárias que não foram produzidas com o objetivo de um trabalho didático de temas científicos pode possibilitar uma abordagem mais significativa para o estudante. A literatura sintetiza, por meios ficcionais, uma realidade que se aproxima da vida cotidiana do leitor. Dessa forma, por mais exacerbada que seja, ela consegue se conectar com o seu destinatário, pois fala sobre o seu mundo, ajuda-o a lidar com suas dificuldades e a conhecê-lo melhor. A articulação da ciência com a literatura pode apresentar um caminho para novas possibilidades de aprendizagem.

Em uma sociedade na qual o conhecimento científico e tecnológico é cada vez mais valorizado, não é possível pensar a formação de um cidadão crítico, sem compreensão do saber científico. A ciência deve ser apresentada como um conhecimento que proporciona a compreensão do mundo e de suas transformações, reconhecendo o homem como parte do universo. Quanto a isso, acreditamos que se faz necessário educar a partir de narrativas diversas, que façam imergir marcos civilizatórios outros sobre a construção do povo negro no Brasil. Dessa forma, concordamos com uma abordagem do ensino de ciências que priorize a diversidade de saberes e possibilite diálogos a partir de narrativas que façam emergir o protagonismo negro e feminino.

Diante dessas informações, pensamos que é possível romper com o ensino de ciências centrado na transmissão de conteúdos e sem significado, através de novas estratégias didáticas que contribuam para uma educação transgressora e libertadora. Paulo Freire coloca em prática um 
trabalho autêntico ao identificar a educação como uma forma de capacitar o estudante tanto para a aquisição da leitura e da escrita, quanto para a sua libertação enquanto sujeito. Por isso, nossa proposta para as relações étnico-raciais nas aulas de ciências é tecida a partir do pensamento de Paulo Freire, aliado à narrativa docente de bell hooks. Acreditamos que esta abordagem nos permita pensar em um ensino verdadeiramente democrático, no qual todos os saberes sejam respeitados e todas as vozes sejam ouvidas.

\section{REFERÊNCIAS}

ADELEKUN, Emanuel. Descubra o significado e por que não usar "breakdancer". PIMENTEL, Evandro (adap.). Publicado em 12 dez. 2019. Disponível em https://www.redbull.com/brpt/danca-por-que-b-boy-b-girl-nao-breakdancer (Não erre mais: de onde vêm os termos B-Boy e B-Girl). Acesso em 31 maio 2021.

ARROYO, Miguel Gonzalez. A função social do ensino de ciências. In: Em aberto, ano 7, n. 40, out./dez., 1988.

CAVALLEIRO, Eliane. Do silêncio do lar ao silêncio escolar: racismo, preconceito e discriminação na educação infantil. São Paulo: Contexto, 2000.

CHASSOT, Attico. Alfabetização científica: questões e desafios para a educação. 3. ed. Ijuí: Editora Unijuí, 2000.

EVARISTO, Conceição. Poemas da recordação e outros movimentos. Rio de Janeiro: Malê, 2017.

FREIRE, Paulo. Pedagogia do oprimido. 17. ed. Rio de Janeiro: Paz e Terra, 1987.

FREIRE, Paulo. Pedagogia da autonomia: saberes necessários à prática educativa. São Paulo: Paz e Terra, 1996.

FREIRE, Paulo. Educação como prática da liberdade. 30. ed. Rio de Janeiro: Paz e Terra, 2007.

FREIRE, Paulo. Extensão on comunicaşão? 15. ed. São Paulo: Paz e Terra, 2011.

FREIRE, Paulo. Pedagogia do oprimido. 71. ed. Rio de Janeiro: Paz e Terra, 2019.

GOMES, Nilma Lino. O movimento negro educador: saberes construídos nas lutas por emancipação. Petrópolis, Rio de Janeiro: Vozes, 2017.

HAMPATÉ BÂ, Amadou. A tradição viva. In: KI-ZERBO, J. (ed.). História Geral da África: I Metodologia e Pré-História da África. 2. ed. Brasília: UNESCO, 2010. p. 167- 212.

HOOKS, bell. Ensinando a transgredir: a educação como prática da liberdade. São Paulo: Editora WMF Martins Fontes, 2013.

HOOKS, bell. Ensinando pensamento crítico: sabedoria e prática. São Paulo: Elefante, 2020.

HOOKS, bell. Minha dança tem história. São Paulo: Boitatá, 2019.

PIASSI, Luís Paulo; ARAÚJO, Paula Teixeira. A literatura infantil no ensino de ciências: propostas didáticas para os anos iniciais do ensino fundamental. São Paulo: Edições SM, 2012.

PINHEIRO, Bárbara Carine Soares. Pedagogia histórico-crítica na formação de professores de ciências. 1. ed. Curitiba: Appris, 2016.

PINHEIRO, Bárbara Carine Soares; ROSA, Katemari (org.). Descolonizando saberes: a Lei 10.639/03 no ensino de ciências. São Paulo: Editora Livraria da Física, 2018.

PONDÉ, Glória. O renascimento de Vênus: a mulher na literatura infantil. São Paulo: SESI SP editora, 2018.

ZILBERMAN, Regina. A literatura infantil na escola. São Paulo: Global, 2003. 
Por que o coronavírus mata mais as pessoas negras e pobres no Brasil e no mundo? Portal de notícias da Globo G1 - Bem-Estar, Brasil, 12 de jul. 2020. Disponível em: Por que o coronavírus mata mais as pessoas negras e pobres no Brasil e no mundo $\mid$ Coronavírus | G1 (globo.com). Acesso em 18 maio 2021.

Submetido em janeiro de 2021

Aprovado em novembro de 2021

\section{Informações das autoras}

Eloize Braga Quintanilha

Pedagoga e Mestranda em Educação em Ciências e Saúde pelo Instituto Nutes de Educação em Ciências e Saúde da UFRJ

E-mail: eloizebraga@hotmail.com

ORCID: https://orcid.org/0000-0003-3432-8971

Link Lattes: http://lattes.cnpq.br/1458434081864051

Fernanda Antunes Gomes da Costa

Professora Adjunta da UFRJ. Pesquisadora no Programa de Pós-graduação em Educação em Ciências e Saúde (NUTES-UFRJ). Dra em Letras (Letras Vernáculas - Literaturas Africanas de Língua Portuguesa)

E-mail: nandantunes80@gmail.com

ORCID: https://orcid.org/0000-0002-1861-3310

Link Lattes: $\underline{\text { http://lattes.cnpq.br/8140849011724900 }}$ 